\title{
Is Amman Stock Exchange an Efficient Market?
}

\author{
Sameer Elbarghouthi \\ Al-Zaytoonah University of Jordan, Department of Accounting, Jordan \\ E-mail: samabr2002@yahoo.com \\ Mohammed Yassin \\ Al-Zaytoonah University of Jordan, Department of Accounting, Jordan \\ E-mail: mmmy1974@yahoo.com \\ Amer Qasim \\ American University of Madaba, Department of Accounting, Jordan \\ E-mail: a.qasim@aum.edu.jo
}

Received: October 5, 2011

doi:10.5539/ibr.v5n1p140

\author{
Accepted: November 23, $2011 \quad$ Published: January 1, 2012 \\ URL: http://dx.doi.org/10.5539/ibr.v5n1p140
}

\begin{abstract}
Recent econometric procedures are employed in this paper to investigate the behavioural properties of Amman Stock Exchange (ASE) indices. Box-Jenkins estimation, irrespective of the index examined, produced different models with a high prediction performance, violating the EMH conditions. The unit-root test also confirmed these results since the return series for all indices did not exhibit unit root, and all processes were stationary.
\end{abstract}

Keywords: Market efficiency, Box-Jenkins Estimation, Stationary and Random Walk Tests, Amman Stock Exchange.

\section{Introduction}

Efficiency, in the context of capital markets, is commonly assumed to refer to the incorporation of the expectation and information of all market participants into the prices of financial assets. If markets are sufficiently competitive, and therefore efficient, then microeconomic theory states that investors cannot earn abnormal profits from their investment strategies. This concept of an efficient capital market has been continuously developed, studied, tested and challenged ever since the French mathematician Bachelier introduced the notion in his PhD thesis in 1900. In his work, Bachelier recognized that "past, present and even discounted future events are reflected in market price, but often show no apparent relation to price changes". He concluded that commodity prices fluctuate randomly, which was empirically supported by Cowles (1933), however largely ignored until Cootner (1964) published Bachelier's contribution in English. The introduction of electronic computers into time series research in the 1950's enabled economists to analyze the behavior of lengthy economic time series, fueling research on the topic of efficient markets. Samuelson (1965) expanded on Bachelier's theory in his article "Proof that Properly Anticipated Prices Fluctuate Randomly." This work, considered the beginning of modern economic literature, asserts that "if one could be sure that a price would rise, it would have already risen" and explains changes in price with the random walk model.

\subsection{Random Walk Model}

Although the origins of the random walk model began with Bachelier (1900) explained a random walk with an analogy to a drunk who staggers in an unpredictable and random fashion. The drunk is just as likely to end up where he began his stagger as at any other point.

\subsection{Efficient Market Hypothesis}

Widely acknowledged today, the Efficient Market Hypothesis (EMH) is a historical compilation of work, which begins with Bachelier's foundations. The EMH has historically been subdivided into three categories as follows:

Weak form efficiency: Prices fully reflect historical information of past prices and returns.

Semi-strong form efficiency: Prices fully reflect all information known to all market participants (public information). 
Strong form efficiency: Prices fully reflect all information known to any market participant (public and private information). From this idea of information sets, Fama (1970) assembled a comprehensive review of theoretical and empirical evidence of market efficiency in which he deems an efficient market as "a market in which prices always 'fully reflect' available information."

In an efficient market, trading on available information fails to provide an abnormal return. In order to prove or disprove the EMH, a model of "normal" returns must be specified against which the actual returns can be compared. Abnormal returns, the difference between the return on a security and its expected return, are forecasted using the chosen information set. If abnormal returns are found to be unforecastable or "random", the EMH is not rejected. To clarify, abnormal returns should not be confused with excess returns, which are defined as the difference between the actual return and the risk-free rate. Implicit to the EMH is the precondition that the cost of information acquisition and trading are equal to zero. However, these costs are clearly positive, driving Fama (1991) to revise his definition of the EMH to a weaker and economically more sensible version stating "prices reflect information to the point where the marginal benefits of acting on information (the profits to be made) do not exceed marginal costs." Most recently, Fama (1998) modified his definition once again, an adjustment which spawned from the growing body of empirical research of all three forms of the EMH. This definition states that in an efficient market "the expected value of abnormal returns is zero, but chance generates deviations from zero (anomalies) in both directions."

\subsection{Literature Review}

Emerging stock markets have recently attracted increasing attention from both researchers and investors. The great interest is not surprising because during early nineties growth of emerging markets are remarkable. Besides its phenomenal growth, emerging market attracts their low correlation with major developed stock markets, and also stock returns in many emerging markets are noticeable more predictable than developed stock markets because of exhibiting systematic patterns.

El-Erian and Kumar (1995) found some departures from weak-form efficiency in Middle Eastern stock markets, but emphasise the serial dependence is sufficiently weak that it likely has little value in predicting future prices. Their finding is consistent with that of Butler and Malaikah (1992), who found statistically significant autocorrelation in the stock markets of Kuwait and Saudi Arabia. Nourrrendine and Kababa (1998) has also examined the behavior of stock prices in the Saudi Financial Market, seeking evidence for weak-form efficiency, but found that the market is not weak-form efficient. Poshakwale (1996) investigated the weak form efficiency and the day of week effect in the Bombay Stock Exchange using runs test and serial correlation coefficient tests. The results of runs test and serial correlation coefficient tests indicate a nonrandom nature of the series and, therefore, violation of weak form efficiency in the BSE. The other null hypothesis that there is no difference between the returns achieved on different days of the week is also rejected as there is clear evidence that the average returns are different on each day of the week. Mobarek (2000) examined the weak-form efficiency in Dhaka Stock Exchange using the daily price indices of all the listed securities on the DSE for the period 1988 to 1997. The results of both non-parametric tests (Kolmogrov -Smirnov normality test and run test) and parametric tests ( Auto-correlation test, Auto-regression, ARIMA model ) provided evidence that the share return series do not follow the random walk model, and the significant autocorrelation co-efficient at different lags reject the null hypothesis of weak-form efficiency.

Moustafa (2004) examines the behavior of stock prices in the United Arab Emirates (UAE) stock market using daily prices of 43 stocks included in the UAE market index for the period October 2, 2001 to September 1, 2003. He finds that the returns of the 43 stocks do not follow normal distribution. However, the results of runs tests show that the returns of 40 stocks out of the 43 are random at $5 \%$ level of significance. Although the UAE stock market is newly developed and it is still very small, also suffering from infrequent trading, according to his results, the UAE is found to be weak-form efficient.

Pandey (2003) analysed the efficiency of the Indian stock markets by using three Indian stock indices to test the efficiency level in Indian stock market and the random walk nature of the stock market by using the runs test and the Auto Correlation Function ACF (K) for the period from January 1996 to June 2002. The study found that the series of stock indices in the Indian stock market biased the random time series and do not confirming the Random Walk Theory.

Sharma et al. (2009) examined the weak-form efficiency of eleven (11) securities listed on the BSE using weekly data from July 2007 to October 2007 by employing runs test and auto-correlation tests. The study concludes that the BSE is weak-form efficient and the stock prices are having very scrimpy effect on future prices which implies that an investor cannot reap out abnormal profits as the current share prices already reflect the effect of past share prices.

Pradhan et al. (2009) in their paper tried to examine the Efficient Market Hypothesis (EMH) in its weak - form by employing the unit root test on the sample of daily stock returns of National Stock Exchange (NSE) and Bombay 
Stock Exchange (BSE). The sample period lies between Jan.2007 to Jul.2009. The study reveals that Indian Stock market is not weak - form efficient.

Worthington and Higgs (2004) find that Germany and Netherlands are weak form efficient under both serial correlation and runs tests, while Ireland, Portugal and the United Kingdom are efficient under one test or the other. Thus, rests of the markets do not follow a random walk

Tas and Dursonoglu (2005) have confirmed the inefficiency result for Turkey using daily stock returns of ISE 30 indices from the period 1995 to 2004. Dickey-Fuller unit root and runs tests were used in their studies and the results of both tests reject random walk hypothesis in ISE.

Akinkugbe (2005) finds stock markets in Botswana to be weak and semi-strong form efficient. His data includes 738 weekly observations for the period June 1989 to December 2003. Autocorrelation, and Augmented Dickey-Fuller and Phillip-Perron unit root tests were used to investigate the weak form of EMH in Botswana stock exchange. In his study, autocorrelation test show evidence of no serial correlation and the results of both unit root tests indicate a stationary process for stock returns, therefore implying weak-form efficiency.

Using the serial correlation, runs and unit root tests Abeysekera (2001) indicates that the Colombo Stock Exchange (CSE) in Sri Lanka is weak-form inefficient. His data include daily, weekly and monthly returns of the Sensitive Share Index (based on market prices of 24 blue-chip companies listed on the CSE) and a 40-security value weighted index for the period January 1991 to November 1996. The results of three tests consistently reject the random walk hypothesis.

(Abraham et al. 2002) they all use variance ratio tests and runs test on the financial data of different countries for testing random walk hypothesis and found week form efficient these markets are and follow a random walk.

Hassan et al. (2006) conduct a test of efficiency in seven European emerging stock markets. They use International Finance Corporation's weekly stock index data for the period December 1988 through August 2002. Several methods used in their studies including Ljung-Box Q-statistic, runs, and variance ratio tests. According to their results, except Greece, Slovakia, and Turkey, markets in Czech Republic, Hungary, Poland and Russia are found to be unpredictable.

Dragotă et al. (2009) analyze the returns of 18 stocks listed at the BSE first category and of the Romanian capital market indices. 11 the stocks and indices are monitored from their listing (respectively the indexes construction) date to the end of 2006. Dragotă et al. (2009) focus on the weak form efficiency, according to which all of the past prices information is incorporated into the current price and, consequently, there could not be obtained systematic abnormal returns based on historical information on prices. The investigation on the weak form of the efficient market hypothesis is based on the following tests of the random walk hypothesis: the Cowels-Jones test, the runs test and the Multiple Variance Ratio - MVR - approach.

Filis (2006) tested the efficiency level of ASE by performing several tests for the period 2000-2002. These include unit roots $(\mathrm{ADF})$ runs and GARCH effects tests. Furthermore he used the Wilcoxon Signed Rank test for the equality of implied versus historic volatility. He rejected the semi-strong form of efficiency as he found evidence of volatility clustering whereas he accepted the weak form as he found that the returns for this period followed a random walk.

Briefly, the previous studies cannot support or contradict the weak form efficiency in emerging markets. Much work must be conducted to investigate price dynamics in emerging markets. It is interesting to find if ASE is weak-form efficient and to what extent, and to explore the return generating process by using serial correlation and runs tests.

\subsection{Data}

Data tested comprised of the daily prices of the five indices in ASE from $1^{\text {st }}$ January 2000 to $31^{\text {st }}$ December 2008.

\section{Box - Jenkins Estimation}

The Box-Jenkins method of forecasting uses an iterative approach. A number of competing models are identified and estimated through following the next five steps, then the simplest (the one with the smallest number of parameters) and most well performed of these models is selected (Refer also to Appendix 4).

- The first step is to difference the prices series of the indices in order to get stationarity (autocorrelation for price levels indicates non-stationarity). The price changes (first differences of price levels) are more likely to be stationary and hence are investigated (more details for stationarity is presented in Section 6.3).

- The second step is to examine the autocorrelation function (AC) and partial autocorrelation function (PAC) of the data in order to identify the appropriate orders of the AR and MA components. If the autocorrelation function dies off smoothly at a geometric rate, and the partial autocorrelations were zero after one lag, then a first-order autoregressive 
model would be suggested. Alternatively, if the autocorrelations were zero after one lag and the partial autocorrelations declined geometrically, a first-order moving average process would come to mind (Madala, 2001).

- The third step is the estimation of the ARMA model. Different forms of ARMA model are investigated; and in order to test the significance of the estimated parameters, $t$ ratios are applied. If higher orders of the estimated parameter prove to be insignificant, then the significant lower order is considered adequate to describe the process. Insignificant parameters are dropped from the model. The randomness of the residuals of the estimated models is then examined. Hence, the disturbance term must be random if the model is correctly specified. The Akaike Information Criterion (AIC) and the Schwartz Bayesian Criterion (SBC) are used to decide the order of the model by choosing the model which has the minimum AIC and SBC (Refer to Appendix 4). The Ljung Box Q-statistics test for autocorrelated disturbances was also applied; these show that the residuals for the chosen models are uncorrelated. On the other hand, the ARCH LM test indicates heteroscedasticity in the disturbance and a strong ARCH effect in all models. Changes in variance also, referred to as conditional heteroscedasticity or stochastic volatility, can be attributed to variations in the amount and importance of relevant price information. This issue will be investigated in more detail in Section 6.4. The final step is to evaluate the forecast performance of the model (The Theil Inequality Coefficient is used for this purpose).

\subsection{Empirical Results}

The AC and the PAC of the price changes are listed in Table (1) (see appendix 1). As shown in the table, the autocorrelation function, for the all indices, seems to be dead after 1 (or 2) lags, and the partial autocorrelations were close to zero after one or two lag. These results suggest a first or second order autoregressive model. Table (1-2) lists the most suitable ARMR models that describe the price changes for each index.

\subsubsection{Prediction Validity for the Models}

Theil's inequality coefficient $(U)$ measures the prediction accuracy of a model. Theil's inequality coefficient $(U)$ can be calculated through the following equation (Theil, 1970; Farnum and Stanton, 1989):

$$
U=\left(\frac{\sum_{t=1}^{T}\left(\frac{\hat{y}_{t}-y_{t}}{y_{t-1}}\right)^{2}}{\sum_{t=1}^{T}\left(\frac{y_{t}-y_{t-1}}{y_{t-1}}\right)^{2}}\right)^{0.5}, 0 \leq U \leq 1
$$

$y_{t}$ : redicted value of endogenous variable y at time $\mathrm{t}$ (observation $\mathrm{t}$ of $y$ ).

$y_{t}$ : Actual value of endogenous variable $\mathrm{y}$ at time $\mathrm{t}$ (observation $\mathrm{t}$ of $\mathrm{y}$ ).

$\mathrm{T}$ : mber of periods (observations) in the simulations (of the sample).

If $U=0$, then $y_{t}=y_{t}$ for all $\mathrm{t}$, and there is a "perfect fit" between actual and predicted data. The closer the $U$ value to 1 , the weaker is the prediction of the model. Theil's inequality coefficient can be decomposed into the following proportions of inequality.

Bias proportion: indicates the systematic differences in actual and forecasted values.

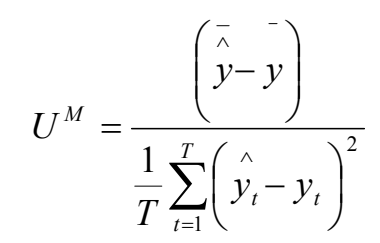

$y, y$ are the means of the series $y_{t}$ and $y_{t}$ respectively.

Variance proportion: indicates unequal variances of actual and forecasted values.

$$
U^{S}=\frac{(\hat{\sigma}-\sigma)^{2}}{\frac{1}{T} \sum_{t=1}^{T}\left(\hat{y_{t}}-y_{t}\right)^{2}}
$$


$\sigma, \sigma$ are the standard deviations of the series $y_{t}$ and $y_{t}$ respectively.

Covariance proportion: indicates the correlation between the actual and forecasted values. (zero=perfect correlation between actual and forecasted values)

$$
U^{C}=\frac{2(1-\rho) \hat{\sigma} \cdot \sigma}{\frac{1}{T} \sum_{t=1}^{T}\left(\hat{y_{t}}-y_{t}\right)^{2}}
$$

$\rho$ is the correlation coefficient between $y_{t}$ and $y_{t}$, and

$$
U^{M}+U^{S}+U^{C}=1
$$

The proportions $\mathrm{U}^{\mathrm{M}}, \mathrm{U}^{\mathrm{S}}$, and $\mathrm{U}^{\mathrm{C}}$ are called the bias, variance, and covariance proportions respectively, and they are useful as a means of breaking the error (difference) down into three characteristic sources.

To test the prediction validity of the models, the models are estimated using the first 2000 observations, then a period of 300 observations ahead is forecasted, and the result in the forecast period is evaluated by using the Theil Inequality Coefficient. Theil Inequality Coefficient is 0 for a perfect forecast and 1 for a naïve static forecast, so under the EMH the coefficient is 1 . Since the coefficient is less than 1 and close to 0 for all models, as shown in Table 6-2, the estimated ARMA models explain price changes better than the random walk model. The bias proportion indicates how far the mean of the forecast is from the mean of the actual series, and the variance proportion indicates how far the variation of the forecast is from the variation of the actual series. If the forecast is good, the bias and variance proportions should be small so that most of the bias should be concentrated on the covariance proportions. Empirically, for all models, the bias and variance proportion is small, indicating that bias is indeed concentrated in the covariance proportion.

These results are also consistent with the findings of Nourredine and Khaba (1998), Roux and Gilberson (1978) and Poshakwale (1996) who found evidence of non-randomness in stock price behaviour and market inefficiency (not weak-form efficient) in the Saudi Arabian Financial Market, Johannesburg Stock Exchange and the Indian Market. In conclusion, the results add to the weight of evidence that emerging markets are not weak-form efficient.

\subsection{Stationary and Random Walk Tests}

Generally speaking, many econometric problems can arise from non-stationarity (Greene, 1997). Granger and Newbold (1974) concluded that if macroeconomic data were integrated, then a regression involving the levels of such data has usually misleading standard significance tests. For example, the conventional $t$ and $F$ tests might incorrectly reject the null hypothesis of the regression, leading to spurious regression. Therefore, economic variables such as stock prices or returns should be modified before using in regression analysis.

The random walk model is:

And the random walk with drift is:

$$
X_{t}=X_{t-1}+\varepsilon_{t}
$$

$$
X_{t}=\alpha+X_{t-1}+\varepsilon_{t}
$$

And the trend stationary process is:

$$
X_{t}=\alpha+\beta t+\varepsilon_{t}
$$

Each of these three series is characterized by a unit root. Granger, Newbold and Phillip conclude that the use of data characterized by unit roots has the potential to lead to serious errors in inferences (Phillips and Perron, 1988; Davidson and MacKinnon, 1993).

However, an alternative test of the weak EMH (beside the serial correlation and runs tests) is based on the random-walk hypothesis (for prices) which is commonly associated with stationarity and a unit root, since the series must exhibit a unit root (non-stationarity) if it is a random walk.

Using,

$$
R_{t}=\ln \left(P_{t}\right)-\ln \left(P_{t-1}\right)
$$

Where $\mathrm{P}$ is the price index, the weak EMH implies, that the log of the price is generated by the following process: 


$$
\ln \left(P_{t}\right)=\beta_{0}+\ln \left(P_{t-1}\right)+\varepsilon_{t}
$$

Which is a random walk with drift in the process generating $\ln \left(P_{t}\right)$. This implies that the $\ln \left(P_{t}\right)$ process has a unit root, an implication which may be tested using standard tests for a unit root in $\ln \left(P_{t}\right)$.

\subsubsection{Tests for Unit Roots}

In order to check the existence of a unit root, the Augmented Dickey-Fuller (ADF) statistic is employed. The test was developed by Dickey and Fuller (1979).

Considering an $\operatorname{AR}(1)$ process with an intercept $\alpha$ :

$$
X_{t}=\alpha+\phi X_{t-1}+\varepsilon_{t}
$$

Where $\alpha$ and $\phi$ are parameters and the $\varepsilon_{t}$ are assumed to be independently and identically distributed with a zero mean and an equal variance. When $-1<\phi<1$, the process $\operatorname{AR}(1)$ is stationary, and if $\phi=1$, then the process is non-stationary and the series is a random walk with drift. The OLS is applied to (11) to obtain $\hat{\phi}$, the estimate of $\phi$, and then a $t$-test is performed for the null hypothesis $H_{0}: \phi=1$ against the alternative hypothesis $H_{A}: \phi<1$. Rejection of the null hypothesis implies stationary series. Some problems arise in such a procedure. First, the OLS estimator $\hat{\phi}$ is biased downwards in small samples, since there is a lagged dependent variable in (11), which poses a risk of concluding that $-1<\phi<1$ and that $\mathrm{X}_{\mathrm{t}}$ is stationary when it is not. Second, if the process is non-stationary, then standard large-sample distribution results are invalid. In order to apply the unit-root test, (11) is rewritten by taking $X_{t-1}$ from each side:

$$
\begin{array}{r}
\Delta X_{t}=\alpha+\phi^{*} X_{t-1}+\varepsilon_{t} \\
\phi^{*}=\phi-1
\end{array}
$$

According to (12) non-stationarity is rejected $\left(\phi^{*}=0\right)$ if the OLS estimate of $\phi^{*}$ is sufficiently negative. Dickey and Fuller have performed extensive simulation studies to tabulate the large-sample distribution of the $t$ ratio under the null hypothesis that $\phi^{*}=0$. The $t$ ratio is distributed not about zero because of a downward bias, as it would be if the OLS estimator were unbiased, but about a value that is less than zero (Hegazy, 1998).

As assumed in (11), the disturbance is a white noise and the equation is first order AR. If this is not a sensible assumption, the above Dickey - Fuller test is invalid in such circumstances. The Augmented Dickey-Fuller test, that modifies the actual testing procedure by generalizing equation (11) is used to test stationarity in such cases. By generalizing (11) into the $\mathrm{r}^{\text {th }}-$ order, then:

$$
X_{t}=\alpha+\phi_{1} X_{t-1}+\phi_{2} X_{t-2}+\ldots . .+\phi_{r} X_{t-r}+\varepsilon_{t}
$$

Reparameterize (14) to obtain:

$$
\Delta X_{t}=\alpha+\phi^{*} X_{t-1}+\phi_{1}^{*} \Delta X_{t-1}+\phi_{2}^{*} \Delta X_{t-2}+\ldots . .+\phi_{r-1}^{*} \Delta X_{t-r+1}+\varepsilon_{t}
$$

Where $\phi^{*}=\phi_{1}+\phi_{2}+\ldots . .+\phi_{r-1}$ and the other $\phi_{j}{ }^{*}$ are also functions of the original $\phi_{s}$ in (14). As noticed, the regressor in the original equation (11) has been augmented by extra differenced terms in equation (14), and is written sometimes as ADF (k), where $\mathrm{k}$ is the number of differenced terms included on the right-hand side of (14). The question is what order of AR process best fits the time series under study to determine the differenced terms to be included on the right-hand side of (14). Usually, the differenced terms should be included up to the limit which produces non-autocorrelated OLS residuals. The LM tests for autocorrelation are usually used for this purpose.

Testing the $\mathrm{r}^{\text {th }}$ order process (14) for stationarity now is testing whether or not $\phi^{*}=0$ in (15)To test $H_{0}: \phi^{*}=1$ the OLS is applied to (15) and the $t$ ratio is examined using the critical $t$ ratios table developed by Dickey-Fuller. If $\phi^{*}$ is sufficiently negative, the $H_{0}$ is rejected in favour of stationarity.

\subsubsection{Deterministic and Stochastic Trends}

Two kinds of trends can appear in the process; deterministic or stochastic trends. Considering nesting the three models (16), (17), (18) in a single equation:

$$
X_{t}=\alpha+\phi X_{t-1}+\beta t+\varepsilon_{t}, \quad \alpha \neq 0
$$


Where $\varepsilon_{t}$ is a white noise and t a time trend. A stochastic trend appears if $\phi=1$ and $\beta=0$. Then

$$
\Delta X_{t}=\alpha+\varepsilon_{t}
$$

$\mathrm{X}_{\mathrm{t}}$ trends upwards or downwards depending on the sign of $\alpha$. This kind of trend can be removed by first-differencing. $\mathrm{X}_{\mathrm{t}}$ is then referred to as a difference stationary.

The deterministic trend appears if $\phi=0$ and $\beta \neq 0$. Then:

$$
X_{t}=\alpha+\beta t+\varepsilon_{t}
$$

$X_{t}$ trends upwards or downwards depending on the sign of $\beta$. This kind of trend cannot be removed by first-differencing, since $t$ doesn't remove from the process. $X_{t}$ is then referred to as a trend stationary process. Stochastic and deterministic trends are present if $\phi=1$ and $\beta \neq 0$. The previous ADF test tests only for the non-stationarity of a stochastic trend. Since both types of trends cause spurious regression problems, Dickey and Fuller suggest an $\mathrm{F}$ test to detect a deterministic trend, by rewriting (16) as:

$$
X_{t}=\alpha+\phi^{*} X_{t-1}+\beta t+\varepsilon_{t}
$$

Where $\phi^{*}=\phi-1 . F$-test is used to test the joint hypothesis $\beta=\phi^{*}=0$ (critical values of $F$ obtained by Dickey Fuller simulation experience since $F$ statistic has a non-standard distribution under the null hypothesis of stochastic trend). Failure to reject this hypothesis would imply that $X_{t}$ is subject to a stochastic trend only, with the absence of a deterministic trend. To test for a deterministic trend alone, the $t$ ratio on the time trend in (19) can be examined using critical values of the $t$ ratio provided by Dickey - Fuller simulation.

The unit root test with the exploration of time trend and drift for the series was applied as follows:

Estimation of the equation:

$$
\Delta X_{t}=\alpha+\beta t+\phi^{*} X_{t-1}+\phi_{1}{ }^{*} \Delta X_{t-1}+\phi_{2}{ }^{*} \Delta X_{t-2}+\ldots . .+\phi_{r-1}{ }^{*} \Delta X_{t-r+1}+\varepsilon
$$

To determine the order of differenced terms included in the equations in order to achieve ADF test, the serial correlation LM test is applied. If LM suggests autocorrelated residuals for the equation (19), then a higher AR process is tried and so on till the LM statistics are satisfactory. The serial correlation LM test is an alternative test for general serial correlation. It uses the Breusch-Godfrey large sample test for autocorrelated disturbances. After determining the sufficient number of lagged differences, the ADF test is applied to the series.

Testing the null hypothesis $H_{0}:\left(\alpha, \beta t, \phi^{*}\right)=(\alpha, 0,0)$ against the alternative hypothesis $H_{A}:\left(\alpha, \beta t, \phi^{*}\right) \neq(\alpha, 0,0)$, through the application of the Wald (coefficient restrictions) test by imposing zero coefficients on $\beta \mathrm{t}, \phi^{*}$. The computed value $\left(\Phi_{1}\right)$ of the Wald test (F-statistic) was compared with the critical value taken from the Dickey and Fuller (1981) tables, which is 6.25 under $95 \%$ significance level. If the result accepts $H_{0}$ (computed value of $\Phi_{1}<6.25$ ), Path $\mathrm{A}$ is followed. If $H_{0}$ is rejected, Path B is followed.

Path A: there is a unit root $\left(\phi^{*}=0\right)$ with no trend $(\beta \mathrm{t}=0)$, with possible drift. To reinforce the inference that the series contains a unit root, the reported value of the $t$-statistic of the coefficient $\phi^{*}$ must be smaller than the critical value obtained from the Dickey and Fuller (1981) tables. To investigate the presence of the drift component, $\Phi_{2}$ is used to test $H_{0}:\left(\alpha, \beta t, \phi^{*}\right)=(0,0,0)$ against the alternative hypothesis $H_{A}:\left(\alpha, \beta t, \phi^{*}\right) \neq(0,0,0)$, the tabulated value for the F statistic of 4.68 from Dickey and Fuller (1981) tables was used. If $H_{0}$ is rejected, then the series is a random walk with drift, otherwise, it is a random walk without drift. Then the equation (21) is estimated.

$$
\Delta X_{t}=\alpha+\phi^{*} X_{t-1}+\phi_{1}{ }^{*} \Delta X_{t-1}+\phi_{2}{ }^{*} \Delta X_{t-2}+\ldots . .+\phi_{r-1}{ }^{*} \Delta X_{t-r+1}+\varepsilon
$$

The F-test $\Phi_{3}$ is used to test $H_{0}:\left(\alpha, \phi^{*}\right)=(0,0)$ against $H_{A}:\left(\alpha, \phi^{*}\right) \neq(0,0)$ using the tabulated critical value for the F statistic of 4.59 from Dickey and Fuller (1981) tables. If $H_{0}$ is rejected then the series is random walk with drift, otherwise, it is random walk without drift.

Path B: Either [ $\beta t \neq 0$ and $\left.\phi^{*}=0\right]$, [ $\beta t=0$ and $\left.\phi^{*} \neq 0\right]$ or $\left[\beta t \neq 0\right.$ and $\phi^{*} \neq 0$ ]. To test if $\phi^{*}=0$, the reported $t$ statistic of $\phi^{*}$ coefficient is compared with the critical value taken from the standard normal tables. If $\phi^{*}=0$ is rejected, then the series does not have a unit root and is considered stationary, otherwise it has a unit root. To test if $\beta t$ $=0$, the reported $t$ statistic of the $\beta \mathrm{t}$ coefficient is compared with the critical value taken from the standard normal tables. If $\beta t=0$ is rejected, then the series has linear trend, otherwise it has no linear trend. To test if the intercept is zero, the $t$ statistic test for $\alpha$ is applied. If $\alpha=0$ then the series is without intercept. Otherwise, it has a non-zero drift. 


\subsubsection{Empirical Results}

The unit root test was conducted first for the five price indices series, then to the five return series. The result in Table 3 shows that the computed values of $\Phi_{1}$ for the general, bank, and insurance price indices are less than 6.25, implying a unit root. Analysing the calculated t-statistic of the coefficient $\phi^{*}$ and comparing it with the critical values obtained from the Dickey and Fuller (1981) tables supports this conclusion. Additionally, the computed values of $\Phi_{2}$ for the mentioned series are less than 4.68, implying the absence of a drift in these processes. Then (4.36) is estimated since $\beta \mathrm{t}$ $=0$ as inferred from the $\Phi_{1}$ test. The $\Phi_{3}$ values are also under the critical values, leading to the conclusion that the series are random walk without drift. From the sequence of these tests, the conclusion is that the three series contain a unit root but not a deterministic trend or a drift term.

For the industry and the service price indices, the values of $\Phi_{1}$ is higher than 6.25 (even though the value is very close to 6.25 in the industry index). Comparing the reported $t$ statistic of $\phi^{*}$ coefficients $(-3.334,-4.09$ respectively) with the critical value of 1.96 taken from the standard normal tables, the $H_{0 \text { : }}$ of $\phi^{*}=0$ is rejected, implying no unit root. The two series have also reported a $t$ statistic of coefficients $\beta \mathrm{t}$ of -3.6 and -3.84 respectively, comparing with the critical value of 1.96. This implies a linear trend, possibly with an intercept. Using a conventional $t$-test in order to test whether the intercept is zero, the $t$ - statistic for the two indices was found to be 3.48 and 4.18 respectively, thereby rejecting the null hypothesis and implying a drift. As a conclusion, the industry and service price indices are stationary with a linear trend and a non-zero drift.

On the other hand, all indices of stock prices exhibited a unit root when different specifications for a unit root were used, such as different number of lags, with or without intercept, with or without trend, and the combinations of these alternatives.

Whilst the price indices series showed deterministic or stochastic trends, nevertheless, the presence of a unit root (non-stationarity) in stock prices is only a necessary (but not sufficient) condition for a random-walk process. As Campbell et al. (1997) demonstrated, unit root tests only explore the permanent/temporary nature of shocks to the series and, as such, have no bearing on the random-walk hypothesis (or predictability). In this light, the use of unit root tests to examine the random-walk hypothesis appears doubtful. See Liu et al. (1997) and Long et al. (1999).

Moreover, the random walk model needs to fit the model ARIMA $(0,1,0)$ where the future value of share prices cannot be determined on the basis of past information. Specifically, future share prices will not depend on past (lag) values of share prices or on the disturbance terms as mentioned in Section 1.2. The significant coefficients different from zero suggest dependency of the series in variables other than simply $P_{t-1}$, and this violates the assumption of a random walk model and weak-form efficiency.

On the other hand, when the unit root test was performed using the return indices, none of them (as shown in Table 4. exhibited a unit root; that is, as expected, all the indices of stock returns are stationary. As the return is the log for first difference of the prices, the price series can be considered as I (1) series, whilst returns are I (0) (Refer to Appendix 4 and note 6).

However the hypothesis of random walk is rejected, for the return indices, by the Dickey-Fuller test at a very high level of confidence (>99\%). Those results lead us to the conclusion, at this stage, that the random walk model is not satisfactory for ASE returns. Note that rejection of random walk in itself does not imply stationarity. However, these results are in line with the results reported by Neaime (2002) which suggested that, according to the (ADF) tests results, the MENA (Middle East and North Africa) stock market price series are non-stationary. However, unit roots in the first differences of the stock prices are rejected at the 1 percent significance level, suggesting that price indices in the MENA regions are I (1).

\section{Conclusion}

This paper has investigated empirically some important aspects of price indices and return behaviour properties for the ASE. The Efficient Market Hypothesis has been assessed using recent econometric procedures. The Box-Jenkins estimation, irrespective of the index examined, produced models with high prediction validity; this implies the existence of deviations from market efficiency in the pricing of equities in the ASE. The unit-root test also confirmed these results, as the return series for all indices did not exhibit unit root and all processes were stationary. Although, the prices series for the general, bank, and insurance indices, exhibited unit roots, it is not sufficient for a random walk process since the series did not fit the ARIMA $(0,1,0)$ model. As Campbell et al. (1997) demonstrated, unit root tests only explore the permanent/temporary nature of shocks to the series and, as such, have no bearing on the random-walk hypothesis or predictability.

The findings of this study are consistent with the results achieved by studies conducted in emerging markets which used different statistical tools and techniques to test the weak form efficiency of stock markets in Middle Eastern stock 
markets (El-Erian and Kumar, 1995), Kuwait and Saudi Arabia (Butler and Malaikah, 1992), Saudi Financial Market (Nourrrendine and Kababa, 1998), Dhaka Stock Exchange Mobarek, 2000), Indian stock market (Pandey, 2003; Pradhan et al.2009), Turkey (Tas and Dursonoglu, 2005).

However, the current study suffers from data selection limitation. As mentioned earlier, data used in this study covered the period January 2000 till December of 2008. Therefore, the study did not test the efficiency of ASE after the financial crises of 2008. This is due to the fact that quoted prices for 2010 were not available at the time of executing this study. Consequently, it is suggested that future research carried out in the Middle Eastern context should include periods before and after the financial crises of 2008 to test its impact on market efficiency. Furthermore, future research is suggested to study the interrelationship between market liquidity and efficiency. Also, cultural factors (e.g. religious, market regulations, and level of professionalism) might be tackled in this area.

\section{References}

Abraham, A., Seyyed, F. J., \& Alsakran, S. A. (2002). Testing the random behavior and efficiency of the Gulf stock markets. The Financial Review, 37(3), 469-480. http://dx.doi.org/10.1111/0732-8516.00008

Bachelier, L. (1900). Theory of Speculation. In Cootner (1964), 17-78.

Campbell, J., A. Lo, \& C. MacKinlay. (1997). The econometrics of financial markets. (1st ed.), New Jersey: Princeton University Press, (Chapter 4).

Chakraborty, M. (2006). Market Efficiency for the Pakistan Stock Market. South Asia Economic Journal, 7 (1), 67-81. http://dx.doi.org/10.1177/139156140500700104

Choudhry, T. (1994). Stochastic trends and stock prices: an international inquiry. Applied Financial Economics, 4, 383-390. http://dx.doi.org/10.1080/758518670

Cootner, P. H. (1964). The Random Character of Stock Market Prices. Cambridge MA: MIT Press.

Cowles, A. (1933). Can Stock Market Forecasters Forecast? Econometrica, 1, 309-324. http://dx.doi.org/10.2307/1907042

Dragotă, Victor, Stoian, Andreea M., Pele, Daniel T., Mitrică, Eugen, \& Bensafta, Malik. (2009). The Development of the Romanian Capital Market: Evidences on Information Efficiency, Romanian Journal of Economic Forecasting, 10, 147-160.

El-Erian, M., \& M. Kumar. (1994). Emerging Equity Markets in Middle Eastern Countries. In ternational Monetary Fund, Middle Eastern and Research Departments, Working Paper WP/94/103.

Eriotis Nik., Vasiliou Dim., \& Papathanasiou Sp. (2008). Testing Technical Anomalies in Athens Stock Exchange. European Research Studies Journal, 9(3 - 4), 75-90.

Fama, E. (1970). Efficient Capital Markets: A Review of Theory and Empirical Work. Journal of Finance, 25, 383-417. http://dx.doi.org/10.2307/2325486

Fama, E. F. (1991). Efficient capital markets: II. Journal of Finance, 46(5), 1575-1617. http://dx.doi.org/10.2307/2328565

Fama, E., \& K. French. (1998). Value versus Growth: International Evidence. Journal of Finance, 53, 1975-2000. http://dx.doi.org/10.1111/0022-1082.00080

Farnum N., \& L. Stanton, (1989) Quantitative Forecasting Methods. Wadsworth Publishing Company

Filis, G. (2006). Testing for Market Efficiency in Emerging Markets: Evidence from the Athens Stock Exchange. Journal of Emerging Market Finance, 5, 121-133. http://dx.doi.org/10.1177/097265270600500201

Granger, C., \& A. Anderson. (1978). An Introduction to Bilinear Time Series Models. Gottingen: Vaden hoeck and Reprecht.

Greene, W. (2000). Econometric Analysis. (4th ed.). Prentice Hall.

Hasanov, Mubariz \& Omay, Tolga. (2007). Are the Transition Stock Markets Efficient? Evidence from Non-Linear Unit Root Tests. Central Bank Review, 2, 1-12.

Hegazy, Z. (1998). Price Performance and Egyptian Stock Market Efficiency: An Initial Public Offerings Perspective. PhD thesis, Strathclyde University.

Hsieh, D. (1995). Non-linear Dynamic in Financial Markets: Evidence and Implications. Financial Analysts Journal, 55-62. http://dx.doi.org/10.2469/faj.v51.n4.1921.

Maddala, G. (2001). Introduction to Econometrics. (3rd ed.). Wiley. 
Moberek, A., \& Keasey, K. (2000). Weak form market efficiency of an emerging market: Evidence from Dhaka stock market of Bangladesh. ENBS conference, Oslo, May. [Online] Available: http://www.e-m-h-org/MoKe00.pdf. (June $8,2008)$.

Moustafa, M. A. (2004). Testing the Weak-Form Efficiency of the United Arab Emirates Stock Market. International Journal of Business, 29(3), 310-325.

Neaime, S. (2002). Liberalization and Financial Integration of MENA Stock Markets. A paper presented at the ERF's 9th Annual conference on "Finance \& Banking" held in Al-Sharja - United Arab Emirates, 26-28 October 2002.

Nourredine Khababa. (1998). Behavior of Stock Prices in the Saudi Arabian Financial Market: Empirical Research Findings. Journal of Financial Management \& Analysis, 11, 48-55.

Opong, K., G., Mulloholland, A. Fox, \& k. Farahmand. (1999). The behaviour of some UK equity indices: an application of Hurst and BDS tests. Journal of empirical finance, 6, 267-282. http://dx.doi.org/10.1016/S0927-5398(99)00004-3

Pandey A. (2003). Efficiency of Indian Stock Market. Time Series Course.]

Philips, B., \& P. Perron. (1988). Mean Reversion in Stock Prices. Journal of Financial Economics, 27-59.

Poshakwale, S. (1996) Evidence on the Weak -Form Efficiency and the Day of the Week Effect in the Indian Stock Market. Finance India, 10, 605-616.

Pradhan, B. B., Das, K. B., \& Mishra, P. K. (2009). Empirical Evidence on Indian Stock Market Efficiency in Context of the Global Financial Crisis. Global J. Finance Manage, 1(2), 149-157.

Roux \& Gilbertson. (1978). The behaviour of share prices on the Johannesburg Stock Exchange. Journal of Business Finance \& Accounting, 5, 223-232. http://dx.doi.org/10.1111/j.1468-5957.1978.tb00185.x

Samuelson, P. (1965). Proof That Properly Anticipated Prices Fluctuate Randomly. Industrial Management Review, 6 , 41-49.

Sewell, S. S., Stansell, I. Lee, \& M. Pan. (1993). Nonlinearities in emerging foreign capital markets. Journal of Business Finance and Accounting, 20, 237-248. http://dx.doi.org/10.1111/j.1468-5957.1993.tb00662.x

Sharma, G. D, Mahendru, M (2009). Efficiency Hypothesis of the Stock Markets: A Case of Indian Securities. Int. J. Bus. Manage, 4(3).

Tas, O., \& Dursonoglu, S. (2005). Testing random walk hypothesis for Istanbul Stock Exchange. International Trade and Finance Association Conference Pape. [Online] Available: http://services.bepress.com/otfa/15th/art38 (March 23, 2006).

Theil, H. (1970). Economic Forecasts and Policy. (2nd ed.) Amsterdan: North Holland Publishing Company.

Willey, T. (1992) Testing for nonlinear dependence in daily stock indices. Journal of Economics and Business, 44, 63-76. http://dx.doi.org/10.1016/0148-6195(92)90007-W 
Table 1. AC and PAC for price changes of the five indices

\begin{tabular}{|c|c|c|c|c|c|c|c|c|c|c|}
\hline Lags & \multicolumn{2}{|c|}{ General } & \multicolumn{2}{c|}{ Banks } & \multicolumn{2}{c|}{ Insurance } & \multicolumn{2}{c|}{ Industry } & \multicolumn{2}{c|}{ Service } \\
\hline & $\underline{\mathrm{AC}}$ & $\underline{\mathrm{PAC}}$ & $\underline{\mathrm{AC}}$ & $\underline{\mathrm{PAC}}$ & $\underline{\mathrm{AC}}$ & $\underline{\mathrm{PAC}}$ & $\underline{\mathrm{AC}}$ & $\underline{\mathrm{PAC}}$ & $\underline{\mathrm{AC}}$ & $\underline{\mathrm{PAC}}$ \\
\hline 1 & $0.266^{* *}$ & $0.266^{* *}$ & $0.227^{* *}$ & $0.227^{* *}$ & $0.196^{* *}$ & $0.196^{* *}$ & $0.259^{* *}$ & $0.259^{* *}$ & $0.22^{* *}$ & $0.22^{* *}$ \\
\hline 2 & 0.013 & $-.063^{* *}$ & 0.018 & -0.035 & 0.029 & -0.01 & 0.022 & $-0.048^{*}$ & $0.054^{* *}$ & 0.007 \\
\hline 3 & -0.02 & -0.008 & -0.01 & -0.006 & $0.058^{* *}$ & $0.056^{*}$ & -0.04 & -0.035 & 0.024 & 0.011 \\
\hline 4 & -0.028 & -0.021 & -0.023 & -0.019 & $0.044^{*}$ & 0.023 & -0.04 & -0.017 & 0.004 & -0.004 \\
\hline 5 & -0.019 & -0.007 & -0.025 & -0.016 & -0.015 & -0.03 & 0.001 & 0.016 & -0.031 & -0.033 \\
\hline 6 & 0.01 & 0.017 & 0.013 & 0.023 & -0.023 & -0.018 & 0.023 & 0.018 & -0.01 & 0.003 \\
\hline 7 & -0.012 & -0.023 & -0.022 & -0.033 & 0.004 & 0.009 & 0.025 & 0.013 & -0.029 & -0.027 \\
\hline 8 & -0.015 & -0.006 & -0.024 & -0.013 & 0.016 & 0.016 & 0.002 & -0.009 & -0.002 & 0.011 \\
\hline 9 & -0.006 & -0.001 & -0.019 & -0.011 & -0.005 & -0.008 & 0.014 & 0.019 & -0.022 & -0.023 \\
\hline 10 & 0.024 & 0.027 & 0.002 & 0.009 & 0.005 & 0.008 & 0.038 & 0.035 & 0.003 & 0.013 \\
\hline 11 & $0.049^{*}$ & 0.037 & 0.036 & 0.035 & -0.009 & -0.015 & $0.051^{*}$ & 0.036 & -0.003 & -0.005 \\
\hline 12 & -0.017 & $-0.044^{*}$ & -0.023 & $-0.044^{*}$ & -0.03 & -0.028 & -0.01 & -0.035 & 0.018 & 0.019 \\
\hline 13 & -0.01 & 0.01 & -0.018 & -0.002 & -0.018 & -0.006 & 0.021 & 0.038 & -0.011 & -0.019 \\
\hline 14 & $0.055^{* *}$ & $0.061^{*}$ & $0.049^{*}$ & $0.058^{*}$ & 0.014 & 0.021 & $0.044^{*}$ & 0.037 & $0.045^{*}$ & $0.051^{*}$ \\
\hline 15 & 0.032 & 0.002 & 0.032 & 0.008 & 0.033 & 0.031 & 0.015 & -0.006 & 0.032 & 0.014 \\
\hline 16 & 0.016 & 0.008 & 0.022 & 0.013 & 0.035 & 0.027 & 0.008 & 0.004 & 0.005 & -0.009 \\
\hline 17 & $0.045^{*}$ & 0.043 & $0.059^{* *}$ & 0.051 & 0.035 & 0.022 & 0.03 & 0.032 & 0.014 & 0.016 \\
\hline 18 & 0.033 & 0.016 & 0.028 & 0.008 & -0.008 & -0.027 & $0.052^{*}$ & 0.042 & 0.007 & -0.003 \\
\hline 19 & 0.015 & 0.007 & 0.017 & 0.014 & 0.022 & 0.025 & 0.008 & -0.018 & $-0.05^{*}$ & -0.05 \\
\hline 20 & -0.017 & -0.024 & -0.003 & -0.011 & -0.003 & -0.014 & -0.03 & -0.029 & -0.029 & -0.008 \\
\hline
\end{tabular}

** Significant at $1 \%$ level,

* Significant at $5 \%$ level

Table 2. Estimated ARMA models for price changes for the five indices

\section{Model: ARMA(2,0)}

Variable Coefficient

$\mathrm{AR}(1) \quad 0.29443$

$\mathrm{AR}(2) \quad-0.077757$

\section{General Index}

$$
\begin{array}{ccl}
\Delta P_{t}=0.294 \Delta P_{t-1} & -0.078 \Delta P_{t-2}+\varepsilon_{t} & \\
\text { Std. Error } & \mathrm{t}-\text { Statistic } & \text { Prob. } \\
0.020616 & 14.28181 & <10^{-5} \\
0.020616 & -3.771788 & 0.0002
\end{array}
$$

\section{Forecast Evaluation}

Theil Inequality Coefficient

$$
\begin{aligned}
& (U) \quad 0.002901 \\
& \left(U^{M}\right) \quad 0.00375 \\
& \left(U^{S}\right)_{0.013755} \\
& \left(U^{C}\right)_{0.982494}
\end{aligned}
$$

Bank Index

$\begin{array}{ll}\text { Bias Proportion } & \left(U^{M}\right) \quad 0.00375 \\ \text { Variance Proportion } & \left(U^{S}\right)_{0.013755} \\ \text { Covariance Proportion } & \left(U^{C}\right)_{0.982494}\end{array}$

Model: ARMA(2,0)

$\begin{array}{lllll}\text { Variable } & \text { Coefficient } & \text { Std. Error } & \text { t-Statistic } & \text { Prob. } \\ & & & & \\ \text { AR(1) } & 0.249815 & 0.020656 & 12.0938 & <10^{-5} \\ \text { AR(2) } & -0.04501 & 0.020656 & -2.178984 & 0.0294\end{array}$

\section{Forecast Evaluation}

Theil Inequality Coefficient

$$
\text { (U) } 0.004064
$$$$
\left(U^{M}\right)
$$

0.001075

$\left(U^{S}\right)_{0.007360}$

Variance Proportion

$\left(U^{C}\right)$

0.991565

Model: ARMA(1,0)

$$
\text { Insurance Index: }
$$

$$
\Delta P_{t}=0.190 \Delta P_{t-1}+\varepsilon_{t}
$$

$\begin{array}{llll}\text { Variable } & \text { Coefficient } & \text { Std. Error } & \text { t-Statistic }\end{array}$ 


\begin{tabular}{|c|c|c|c|c|}
\hline $\mathrm{AR}(1)$ & 0.189507 & 0.02032 & 9.32617 & $<10^{-5}$ \\
\hline \multicolumn{5}{|c|}{ Forecast Evaluation } \\
\hline \multicolumn{2}{|c|}{ Theil Inequality Coefficient } & \multicolumn{3}{|c|}{$\begin{array}{ll}(U) & 0.003388\end{array}$} \\
\hline \multicolumn{2}{|c|}{ Bias Proportion } & \multicolumn{2}{|c|}{0.003159} & \\
\hline \multicolumn{2}{|c|}{ Variance Proportion } & \multicolumn{2}{|c|}{0.001901} & \\
\hline \multicolumn{2}{|c|}{ Covariance Proportion } & \multicolumn{2}{|c|}{$\left(U^{C}\right)_{0.994940}$} & \\
\hline \multicolumn{5}{|c|}{ Industry Index: } \\
\hline \multicolumn{5}{|c|}{$\Delta P_{t}=0.270 \Delta P_{t-1}-0.068 \Delta P_{t-2}+\varepsilon_{t}$} \\
\hline Variable & Coefficient & Std. Error & t-Statistic & Prob. \\
\hline $\mathrm{AR}(1)$ & 0.267926 & 0.020631 & 12.9865 & $<10^{-5}$ \\
\hline $\mathrm{AR}(2)$ & -0.06784 & 0.02063 & -3.288375 & 0.001 \\
\hline \multicolumn{5}{|c|}{ Forecast Evaluation } \\
\hline \multicolumn{2}{|c|}{ Theil Inequality Coefficient } & \multicolumn{3}{|c|}{$\begin{array}{ll}(U) & 0.003306\end{array}$} \\
\hline \multicolumn{2}{|c|}{ Bias Proportion } & \multicolumn{2}{|c|}{0.008005} & \\
\hline \multicolumn{2}{|c|}{ Variance Proportion } & \multicolumn{2}{|c|}{0.009067} & \\
\hline \multicolumn{2}{|c|}{ Covariance Proportion } & \multicolumn{2}{|c|}{$\left(U^{C}\right)_{0.982928}$} & \\
\hline & & & dex: & \\
\hline \multicolumn{5}{|c|}{ Model: ARMA(2,0) } \\
\hline \multicolumn{5}{|c|}{$\Delta P_{t}=0.216 \Delta P_{t-1}+\varepsilon_{t}$} \\
\hline Variable & Coefficient & Std. Error & t-Statistic & Prob. \\
\hline $\operatorname{AR}(1)$ & 0.21557 & 0.020181 & 10.68187 & $<10^{-5}$ \\
\hline \multicolumn{5}{|c|}{ Forecast Evaluation } \\
\hline \multicolumn{2}{|c|}{ Theil Inequality Coefficient } & \multicolumn{3}{|c|}{$(U) \quad 0.002403$} \\
\hline \multicolumn{2}{|c|}{ Bias Proportion } & \multicolumn{2}{|c|}{$\left(U^{M}\right)_{0.003009}$} & \\
\hline \multicolumn{2}{|c|}{ Variance Proportion } & \multicolumn{2}{|c|}{$\left(U^{S}\right) \quad 0.009473$} & \\
\hline & Proportion & $\left(U^{C}\right)_{0.98}$ & & \\
\hline
\end{tabular}

Table 3. Unit Root Tests (Price level of the General Index)

\begin{tabular}{|c|c|c|c|}
\hline \multicolumn{4}{|c|}{ 1) Determining the order of differenced terms included in the equations to achieve ADF test. } \\
\hline \multicolumn{4}{|c|}{ LS // Dependent Variable is D(GENERAL) } \\
\hline Variable & Coefficient & Std. Error & t-Statistic \\
\hline $\mathrm{C}$ & 0.452081 & 0.172718 & 2.617454 \\
\hline GENERAL $(-1)$ & -0.00278 & 0.001223 & -2.27518 \\
\hline Trend & $-1.61 \mathrm{E}-05$ & 3.39E-05 & -0.47576 \\
\hline D(GENERAL(-1)) & 0.293729 & 0.020595 & 14.26228 \\
\hline D(GENERAL(-2)) & -0.07735 & 0.020604 & -3.75423 \\
\hline \multicolumn{4}{|c|}{ 2)Serial Correlation LM Test (suggests no autocorrelated residuals) } \\
\hline \multicolumn{4}{|c|}{ Breusch-Godfrey Serial Correlation LM Test: } \\
\hline F-statistic & 0.582463 & Probability & 0.558602 \\
\hline Obs*R-squared & 1.167835 & Probability & 0.557709 \\
\hline \multicolumn{4}{|c|}{ 3)Wald Test: $H_{0}:\left(\alpha, \beta t, \phi^{*}\right)=(\alpha, 0,0)$} \\
\hline Equation: D(general & $3($ trend $)+c 4(D($ general $(-1))+c 5(D$ & general(-2)) & \\
\hline
\end{tabular}




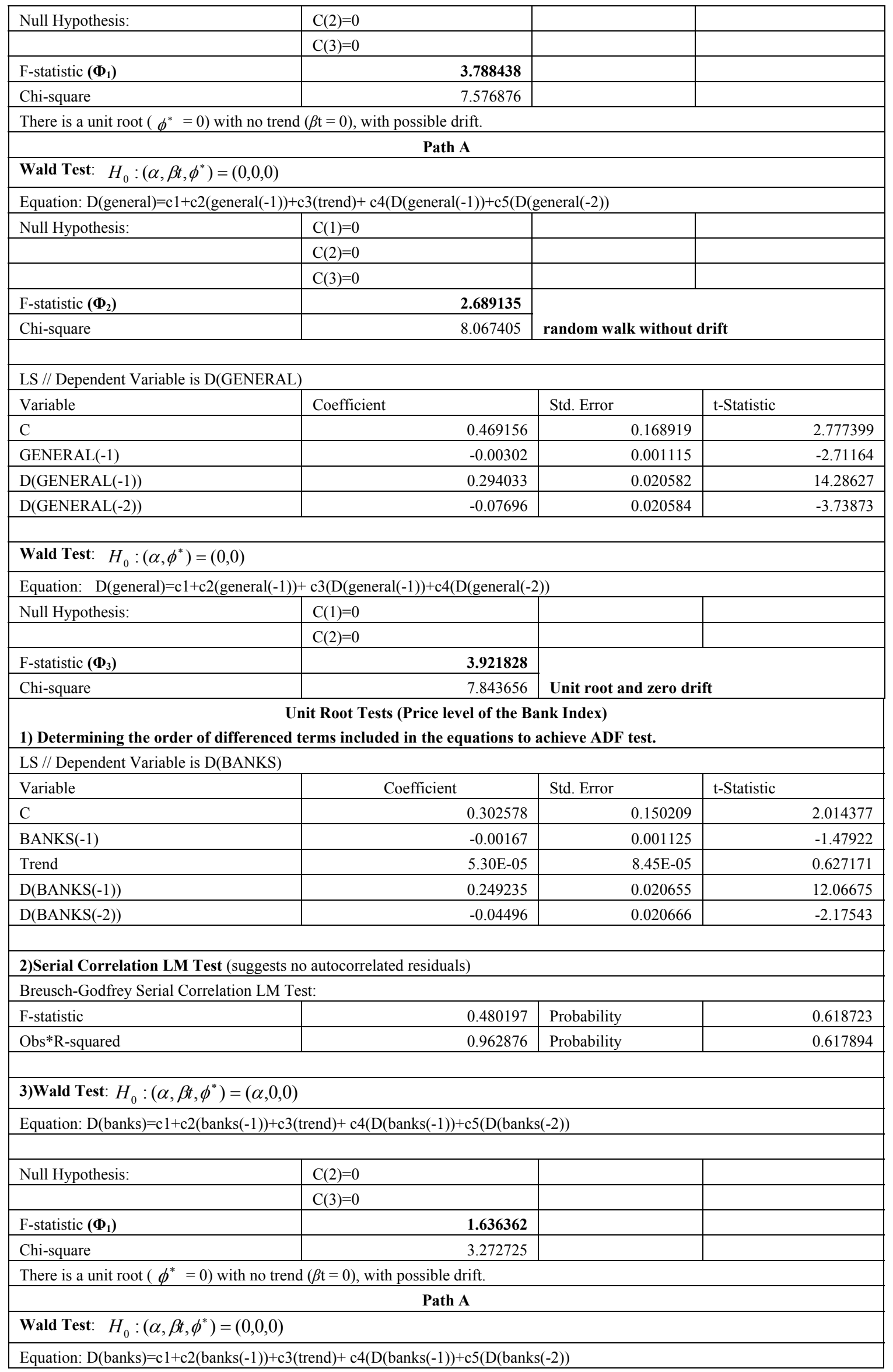




\begin{tabular}{|c|c|c|c|}
\hline Null Hypothesis: & $C(1)=0$ & & \\
\hline & $C(2)=0$ & & \\
\hline & $C(3)=0$ & & \\
\hline F-statistic $\left(\boldsymbol{\Phi}_{2}\right)$ & 1.692606 & \multirow{2}{*}{\multicolumn{2}{|c|}{ random walk without drift }} \\
\hline Chi-square & 5.077818 & & \\
\hline \multicolumn{4}{|c|}{ LS // Dependent Variable is D(BANKS) } \\
\hline Variable & Coefficient & Std. Error & $\mathrm{t}$-Statistic \\
\hline $\mathrm{C}$ & 0.469156 & 0.168919 & 2.777399 \\
\hline BANKS(-1) & -0.00302 & 0.001115 & -2.71164 \\
\hline $\mathrm{D}(\mathrm{BANKS}(-1))$ & 0.294033 & 0.020582 & 14.28627 \\
\hline $\mathrm{D}(\mathrm{BANKS}(-2))$ & -0.07696 & 0.020584 & -3.73873 \\
\hline \multicolumn{4}{|c|}{ Wald Test: $H_{0}:\left(\alpha, \phi^{*}\right)=(0,0)$} \\
\hline \multicolumn{4}{|c|}{ Equation: $\quad \mathrm{D}($ banks $)=\mathrm{c} 1+\mathrm{c} 2($ banks $(-1))+\mathrm{c} 3(\mathrm{D}($ banks $(-1))+\mathrm{c} 4(\mathrm{D}($ banks $(-2))$} \\
\hline \multirow[t]{2}{*}{ Null Hypothesis: } & $\mathrm{C}(1)=0$ & & \\
\hline & $\mathrm{C}(2)=0$ & & \\
\hline F-statistic $\left(\boldsymbol{\Phi}_{3}\right)$ & 2.342845 & \multirow{2}{*}{\multicolumn{2}{|c|}{ Unit root and zero drift }} \\
\hline Chi-square & 4.68569 & & \\
\hline \multicolumn{4}{|c|}{$\begin{array}{l}\text { Unit Root Tests (Price level of the Insurance Index) } \\
\text { 1) Determining the order of differenced terms included in the equations to achieve ADF test. }\end{array}$} \\
\hline \multicolumn{4}{|c|}{ LS // Dependent Variable is D(INSURANCE) } \\
\hline Variable & Coefficient & Std. Error & t-Statistic \\
\hline $\mathrm{C}$ & 0.448257 & 0.172104 & 2.604575 \\
\hline INSURANCE(-1) & -0.00297 & 0.001195 & -2.48546 \\
\hline Trend & $-4.19 \mathrm{E}-05$ & $2.76 \mathrm{E}-05$ & -1.51614 \\
\hline D(INSURANCE(-1)) & 0.193639 & 0.02066 & 9.372631 \\
\hline D(INSURANCE(-2)) & -0.03199 & 0.021025 & -1.5213 \\
\hline D(INSURANCE(-3)) & 0.035181 & 0.021055 & 1.670919 \\
\hline D(INSURANCE(-4)) & 0.032545 & 0.020683 & 1.57352 \\
\hline \multicolumn{4}{|c|}{ 2)Serial Correlation LM Test (suggests no autocorrelated residuals) } \\
\hline \multicolumn{4}{|c|}{ Breusch-Godfrey Serial Correlation LM Test: } \\
\hline F-statistic & 1.486782 & Probability & 0.226313 \\
\hline Obs*R-squared & 2.981238 & Probability & 0.225233 \\
\hline \multicolumn{4}{|c|}{ 3)Wald Test: $H_{0}:\left(\alpha, \beta t, \phi^{*}\right)=(\alpha, 0,0)$} \\
\hline \multicolumn{4}{|c|}{$\begin{array}{l}\text { Equation: } D(\text { insurance })=c 1+c 2(\text { insurance }(-1))+c 3(\text { trend })+c 4(D(\text { insurance }(-1))+c 5(D(\text { insurance }(-2))+ \\
c 6(D(\text { insurance }(-3))+c 7(D(\text { insurance }(-4))\end{array}$} \\
\hline \multirow[t]{2}{*}{ Null Hypothesis: } & $\mathrm{C}(2)=0$ & & \\
\hline & $C(3)=0$ & & \\
\hline F-statistic $\left(\boldsymbol{\Phi}_{1}\right)$ & 3.230248 & & \\
\hline Chi-square & 6.460497 & & \\
\hline \multicolumn{4}{|c|}{ There is a unit root $\left(\phi^{*}=0\right)$ with no trend $(\beta \mathrm{t}=0)$, with possible drift. } \\
\hline \multicolumn{4}{|c|}{$\begin{array}{ll} & \text { Path A } \\
\end{array}$} \\
\hline \multicolumn{4}{|c|}{ Wald Test: $H_{0}:\left(\alpha, \beta t, \phi^{*}\right)=(0,0,0)$} \\
\hline \multicolumn{4}{|c|}{$\begin{array}{l}\text { Equation: } D(\text { insurance })=c 1+c 2(\text { insurance }(-1))+c 3(\text { trend })+c 4(D(\text { insurance }(-1))+c 5(D(\text { insurance }(-2))+ \\
\mathrm{c} 6(\mathrm{D}(\text { insurance }(-3))+c 7(D(\text { insurance }(-4))\end{array}$} \\
\hline \multirow[t]{3}{*}{ Null Hypothesis: } & $\mathrm{C}(1)=0$ & & \\
\hline & $C(2)=0$ & & \\
\hline & $C(3)=0$ & & \\
\hline F-statistic $\left(\Phi_{2}\right)$ & 2.356554 & \multirow{2}{*}{\multicolumn{2}{|c|}{ random walk without drift }} \\
\hline Chi-square & 7.069662 & & \\
\hline \multicolumn{4}{|c|}{ LS // Dependent Variable is D(INSURANCE) } \\
\hline Variable & Coefficient & Std. Error & t-Statistic \\
\hline
\end{tabular}




\begin{tabular}{|c|c|c|c|}
\hline $\mathrm{C}$ & 0.301301 & 0.142253 & 2.118064 \\
\hline INSURANCE(-1) & -0.00222 & 0.001087 & -2.03949 \\
\hline D(INSURANCE(-1)) & 0.193852 & 0.020665 & 9.380557 \\
\hline D(INSURANCE(-2)) & -0.03192 & 0.021031 & -1.51788 \\
\hline D(INSURANCE(-3)) & 0.035343 & 0.02106 & 1.67817 \\
\hline D(INSURANCE(-4)) & 0.032725 & 0.020688 & 1.581806 \\
\hline \multicolumn{4}{|c|}{ Wald Test: $H_{0}:\left(\alpha, \phi^{*}\right)=(0,0)$} \\
\hline \multicolumn{4}{|c|}{ Equation: $\quad \mathrm{D}($ insurance $)=\mathrm{c} 1+\mathrm{c} 2($ insurance $(-1))+\mathrm{c} 3(\mathrm{D}($ insurance $(-1))+\mathrm{c} 4(\mathrm{D}($ insurance $(-2))$} \\
\hline \multirow[t]{2}{*}{ Null Hypothesis: } & $\mathrm{C}(1)=0$ & & \\
\hline & $C(2)=0$ & & \\
\hline F-statistic $\left(\boldsymbol{\Phi}_{3}\right)$ & 2.384168 & \multirow{2}{*}{\multicolumn{2}{|c|}{ Unit root and zero drift }} \\
\hline Chi-square & 4.768335 & & \\
\hline \multicolumn{4}{|c|}{$\begin{array}{l}\text { Unit Root Tests (Price level of the Industry Index) } \\
\text { 1) Determining the order of differenced terms included in the equations to achieve ADF test. }\end{array}$} \\
\hline \multicolumn{4}{|c|}{ LS // Dependent Variable is D(INDUSTRY) } \\
\hline Variable & Coefficient & Std. Error & t-Statistic \\
\hline $\mathrm{C}$ & 0.730324 & 0.209701 & $3.482685 * *$ \\
\hline INDUSTRY(-1) & -0.00455 & 0.001364 & $-3.33469 * *$ \\
\hline Trend & -0.00019 & $5.28 \mathrm{E}-05$ & $-3.59985 * *$ \\
\hline D(INDUSTRY(-1)) & 0.266808 & 0.020582 & 12.96337 \\
\hline D(INDUSTRY(-2)) & -0.06763 & 0.020585 & -3.28516 \\
\hline \multicolumn{4}{|c|}{ 2)Serial Correlation LM Test (suggests no autocorrelated residuals) } \\
\hline \multicolumn{4}{|c|}{ Breusch-Godfrey Serial Correlation LM Test: } \\
\hline F-statistic & 0.805247 & Probability & 0.447101 \\
\hline Obs*R-squared & 1.614208 & Probability & 0.446148 \\
\hline \multicolumn{4}{|c|}{ 3)Wald Test: $H_{0}:\left(\alpha, \beta t, \phi^{*}\right)=(\alpha, 0,0)$} \\
\hline \multicolumn{4}{|c|}{ Equation: $\mathrm{D}$ (industry) $=\mathrm{c} 1+\mathrm{c} 2($ industry $(-1))+\mathrm{c} 3$ (trend) $+\mathrm{c} 4(\mathrm{D}$ (industry $(-1))+\mathrm{c} 5(\mathrm{D}$ (industry $(-2))$} \\
\hline \multirow[t]{2}{*}{ Null Hypothesis: } & $\mathrm{C}(2)=0$ & & \\
\hline & $\mathrm{C}(3)=0$ & & \\
\hline F-statistic $\left(\boldsymbol{\Phi}_{1}\right)$ & 6.713993 & & \\
\hline Chi-square & 13.42799 & & \\
\hline \multicolumn{4}{|c|}{ Path B } \\
\hline \multicolumn{4}{|c|}{ The series is stationary with time trend and intercept. } \\
\hline \multicolumn{4}{|c|}{$\begin{array}{l}\text { Unit Root Tests (Price level of the Service Index) } \\
\text { 1) Determining the order of differenced terms included in the equations to achieve ADF test. }\end{array}$} \\
\hline \multicolumn{4}{|c|}{ LS // Dependent Variable is D(INDUSTRY) } \\
\hline Variable & Coefficient & Std. Error & t-Statistic \\
\hline $\mathrm{C}$ & 1.144109 & 0.273537 & $4.182647 * *$ \\
\hline SERVICES(-1) & -0.0075 & 0.001834 & $-4.08991 * *$ \\
\hline Trend & -0.0002 & $5.15 \mathrm{E}-05$ & $-3.84709 * *$ \\
\hline D(SERVICES(-1)) & 0.215842 & 0.020117 & 10.72925 \\
\hline \multicolumn{4}{|c|}{ 2)Serial Correlation LM Test (suggests no autocorrelated residuals) } \\
\hline \multicolumn{4}{|c|}{ Breusch-Godfrey Serial Correlation LM Test: } \\
\hline F-statistic & 0.17191 & Probability & 0.842066 \\
\hline Obs*R-squared & 0.344651 & Probability & 0.841705 \\
\hline \multicolumn{4}{|c|}{ 3)Wald Test: $H_{0}:\left(\alpha, \beta t, \phi^{*}\right)=(\alpha, 0,0)$} \\
\hline \multicolumn{4}{|c|}{ Equation: $\mathrm{D}($ industry $)=\mathrm{c} 1+\mathrm{c} 2($ services $(-1))+\mathrm{c} 3($ trend $)+\mathrm{c} 4(\mathrm{D}($ services $(-1))+\mathrm{c} 5(\mathrm{D}($ services $(-2))$} \\
\hline \multirow[t]{2}{*}{ Null Hypothesis: } & $\mathrm{C}(2)=0$ & & \\
\hline & $\mathrm{C}(3)=0$ & & \\
\hline
\end{tabular}




\begin{tabular}{|l|r|r|r|}
\hline F-statistic $\left(\boldsymbol{\Phi}_{1}\right)$ & 8.905464 & \\
\hline Chi-square & 17.81093 & \\
\hline \multicolumn{2}{|c|}{ Path B } \\
\hline
\end{tabular}

Table 4. Unit Root Tests (Returns of General Index)

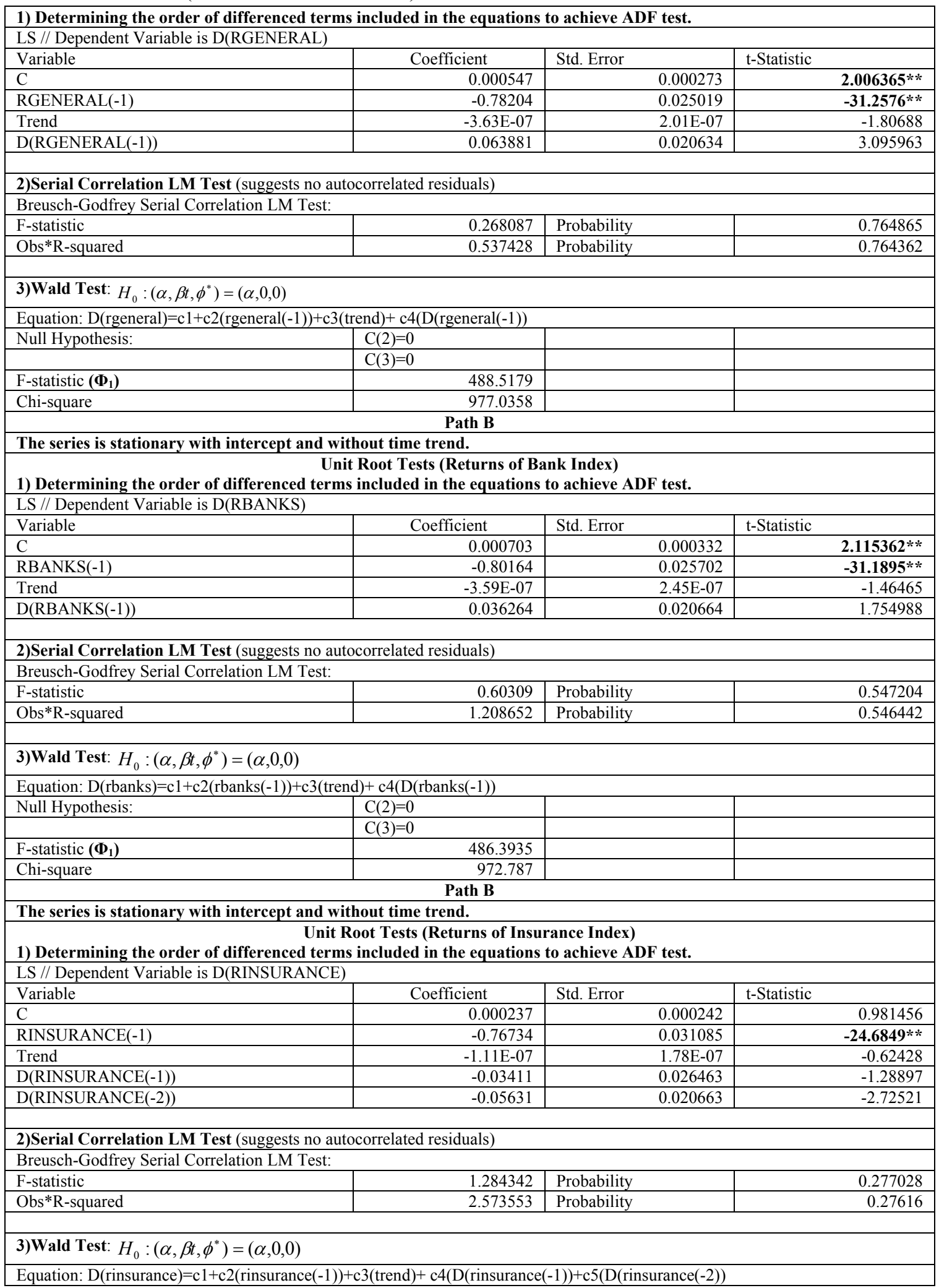




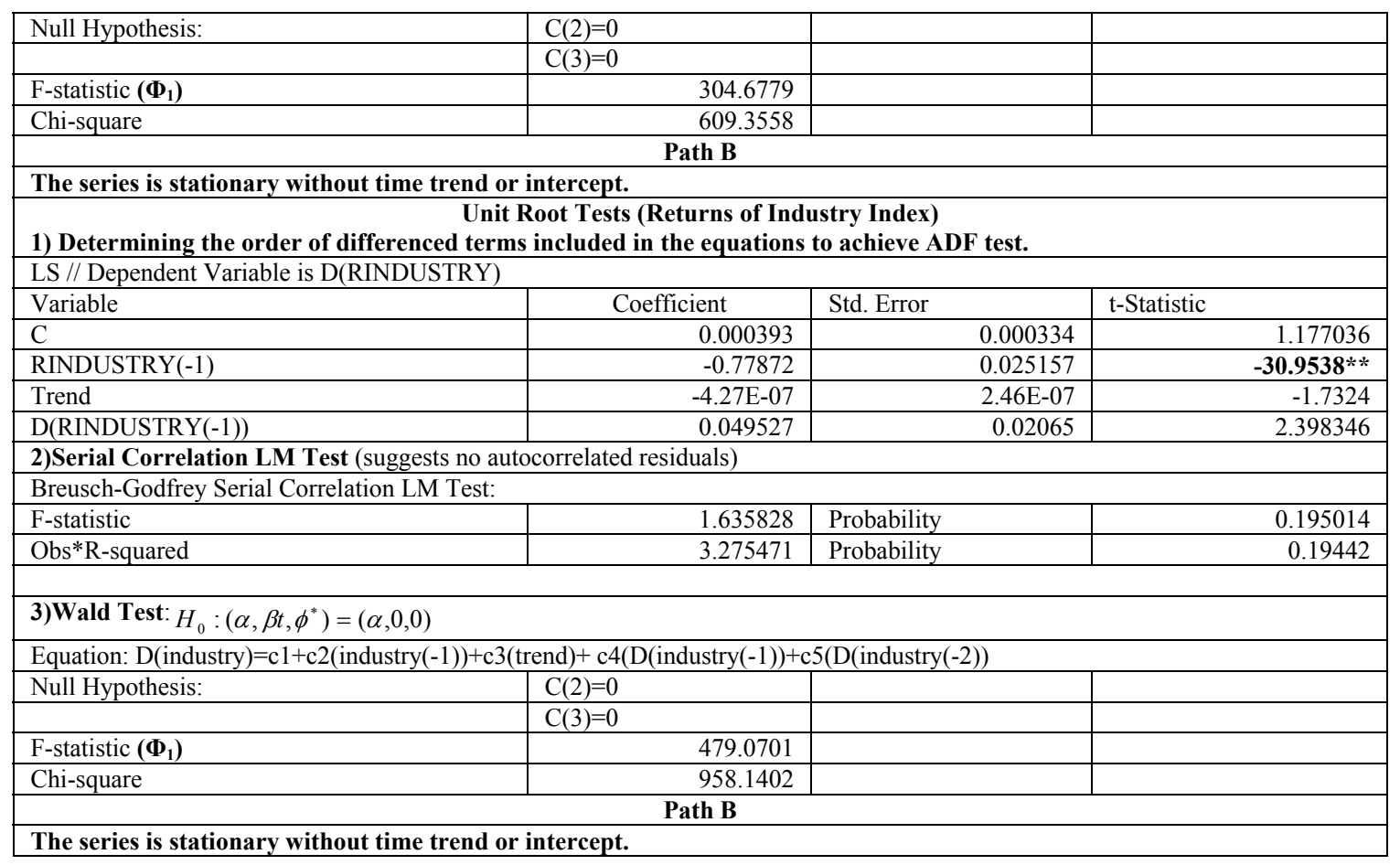

Table 5. Continued: Table 4. Unit Root Tests (Returns of Service Index)

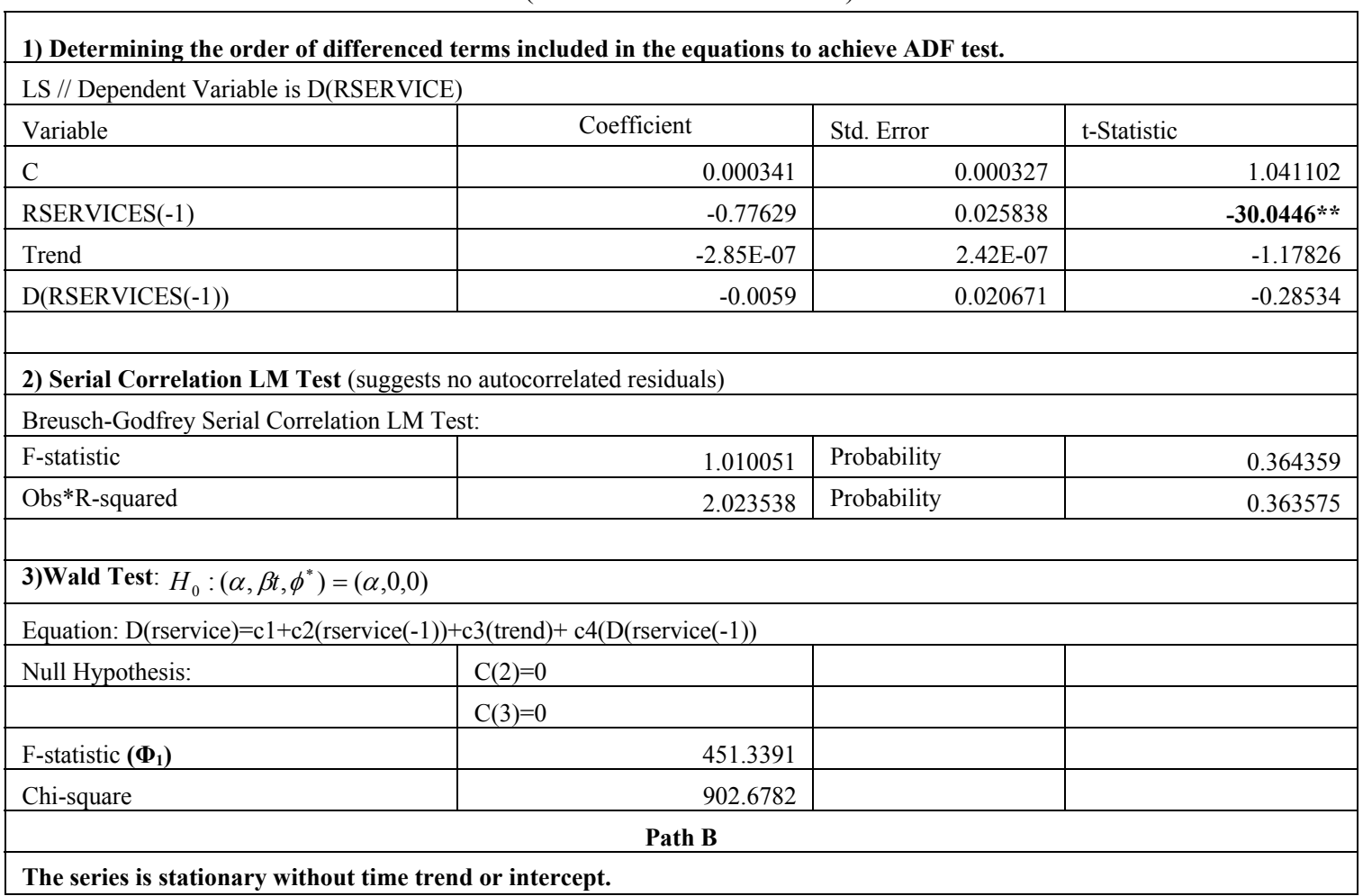

